\title{
Contingent negative variation as a dopaminergic biomarker: evidence from dose-related effects of methylphenidate
}

\author{
Anke M. W. Linssen - Eric F. P. M. Vuurman • \\ Anke Sambeth • Stephane Nave • Will Spooren • \\ Gabriel Vargas • Luca Santarelli • Wim J. Riedel
}

Received: 16 February 2011 / Accepted: 4 May 2011 / Published online: 20 May 2011

(C) The Author(s) 2011. This article is published with open access at Springerlink.com

\begin{abstract}
Rationale The basal ganglia play an important role in motor control, which is dependent on dopaminergic input. Preparation of a motor response has been associated with dopamine release in the basal ganglia, and response readiness may therefore serve as a pharmacodynamic marker of dopamine activity.

Methods We measured response readiness using the amplitude of the contingent negative variation $(\mathrm{CNV})$, a slow negative shift in the electroencephalogram. The CNV is evoked in a paradigm in which a warning stimulus (S1) signals the occurrence of the imperative stimulus (S2) 4 s later, to which the participant has to respond. CNV was assessed in healthy volunteers after administration of placebo or 10,20 or $40 \mathrm{mg}$ of methylphenidate, a catecholamine re-uptake blocker which primarily enhances the synaptic concentration of dopamine and to a lesser extent also noradrenaline. In addition, participants filled out two visual analogue scales measuring subjective ratings of mood and alertness: Profile of Mood States and Bond and Lader.

Results Methylphenidate dose dependently increased CNV amplitude and decreased reaction times. Furthermore, participants reported improved mood, feeling more alert, vigorous and content and less angry and tired after methylphenidate.
\end{abstract}

A. M. W. Linssen $(\bowtie) \cdot$ E. F. P. M. Vuurman · A. Sambeth •

W. J. Riedel

Department of Neuropsychology \& Psychopharmacology, Faculty of Psychology and Neuroscience, Maastricht University, PO Box 616, 6200 MD, Maastricht, the Netherlands

e-mail: anke.linssen@maastrichtuniversity.nl

S. Nave $\cdot$ W. Spooren $\cdot$ G. Vargas $\cdot$ L. Santarelli $\cdot$ W. J. Riedel

F. Hoffmann-La Roche Ltd.,

Basel, Switzerland
Conclusions These results indicate that dopamine availability increases response readiness as measured by the CNV paradigm. The $\mathrm{CNV}$ appears to be a good candidate biomarker for assessing changes in dopaminergic function by treatments that either directly or indirectly target the dopaminergic system.

Keywords Contingent negative variation .

Methylphenidate $\cdot$ Event-related potentials $\cdot$ Response preparation · Dopamine

\section{Introduction}

Dopamine abnormalities are implicated in neuropsychiatric diseases such as Parkinson's disease, schizophrenia and attention deficit hyperactivity disorder (ADHD; Iversen and Iversen 2007; Nieoullon 2002), but the precise nature of these disturbances and their treatments remains to be understood. This drives the relevance of dopamine-related research and the value of new tools aiding this research. In the present study, a candidate biomarker of dopamine activity is proposed and validated.

The contingent negative variation (CNV) is a slow negative shift in the EEG that can be observed between a warning signal and an imperative stimulus during a reaction time task. The occurrence of this wave has been associated with expectation, anticipation, orientation, attention, intention to act, motivation and response readiness (Bares et al. 2003; Tecce 1972; van Boxtel and Brunia 1994; Walter et al. 1964).

Evidence from studies with Parkinson's disease patients using intracranial electrodes and studies combining EEG/ fMRI techniques suggests that the $\mathrm{CNV}$ is generated in the basal ganglia (Bares and Rektor 2001; Fan et al. 2007; Nagai et al. 2007; Oishi et al. 1995; Rektor et al. 2003, 
2004). An important neuromodulator within the basal ganglia is dopamine which, consequently, has been considered a possible biochemical mechanism underlying the $\mathrm{CNV}$ (Amabile et al. 1986). Converging evidence suggests that CNV may indeed be modulated by dopamine availability (Amabile et al. 1986; Kopell et al. 1974; Oishi et al. 1995; Tecce 1991; Tecce and Cole 1974; Tecce et al. 1975). Consequently, changes in CNV may signal alterations of dopamine levels in the brain, and the CNV may thus be a basal ganglia originated marker of dopamine activity.

Research with agents affecting other neurotransmitters such as serotonin, noradrenaline and acetylcholine showed that the influence on the $\mathrm{CNV}$ is indirect (through interactions with the dopamine system), absent or dose dependent (Ashton et al. 1976, 1980; Ashton and Rawlins 1978; Hansenne et al. 2000; Mulder et al. 2002). Benzodiazepines decrease CNV amplitude (Ashton et al. 1976; Papart et al. 1997; Rockstroh et al. 1991).

An early and a late CNV component or 'wave' can be distinguished (Klorman and Bentsen 1975). The early wave is thought of as an orientation response (Klorman and Bentsen 1975) whereas the late CNV consists of a readiness potential and stimulus preceding negativity (Brunia 1988; van Boxtel and Brunia 1994). The late CNV reflects motor preparation and stimulus anticipation (Brunia and van Boxtel 2001) and is the wave targeted here. To observe both waves, an interval of $4 \mathrm{~s}$ is used in the current study.

Before the CNV can be successfully applied as a dopaminergic biomarker, its sensitivity needs to be established. It is essential to know both the minimal change in dopamine levels that can be detected by means of the $\mathrm{CNV}$ and the dose-response curve of the paradigm. Therefore, this study measured CNV amplitude across a range of doses of a dopamine-enhancing drug. The drug chosen was methylphenidate. Methylphenidate inhibits dopamine re-uptake by blocking the dopamine transporter (DAT) and thus enhances dopamine availability (Volkow et al. 1998a), has a wide safe dose range, is generally well tolerated and has been used for similar purposes in previous studies (Volkow et al. 1998b, 2008). Methylphenidate is used to treat ADHD and narcolepsy. The maximum dose in children with ADHD is $60 \mathrm{mg} /$ day. PET research has shown that methylphenidate leads to dose-dependent DAT blockade with a dose of $5 \mathrm{mg}$ producing a $12 \%$

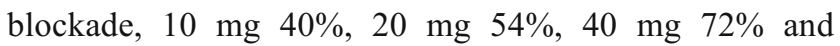
$60 \mathrm{mg} 74 \%$ (Volkow et al. 1998a). Hence, therapeutic doses of methylphenidate are likely to block more than $50 \%$ of DAT. $T_{\max }$ is observed $1-3 \mathrm{~h}$ after intake, with a half life of approximately $3 \mathrm{~h}$ (Leonard et al. 2004; Spencer et al. 2006).

Participants were treated with 10,20 and $40 \mathrm{mg}$ of methylphenidate, and in addition to $\mathrm{CNV}$ amplitude, task performance and subjective drug effects were also measured. It was expected that CNV amplitude would show a doserelated increase and that reaction time would dose dependently decrease. Based on the PET research cited above and other previous studies with methylphenidate (Cooper et al. 2005; Hermens et al. 2007), it was expected that a dose of $10 \mathrm{mg}$ would lead to minimal effects. The largest effects were expected with $40 \mathrm{mg}$ of methylphenidate, whereas $20 \mathrm{mg}$ was expected to induce intermediate effects.

\section{Materials and methods}

\section{Participants}

Nineteen healthy male volunteers (mean age $=23.4, \mathrm{SD}=5.4$, range $=19-37$ ) were selected and paid to participate. Participants were recruited by means of advertisement posters in university buildings and advertisements in the university newspaper. Prescreening occurred using a medical history questionnaire and was followed by medical examination.

The main inclusion criteria were between 18 and 40 years of age, body mass index between 18 and $30 \mathrm{~kg} / \mathrm{m}^{2}$ and right-handed. The main exclusion criteria were history or presence of mental or physical disorders as assessed by medical history and anamnesis at inclusion, reported presence of psychiatric diseases in first degree relatives, previous drug dependence, self-reported regular drug use, smoking more than five cigarettes per day and consumption of more than 21 alcohol units per week or more than five caffeine containing drinks per day (average reported daily use $<2$ ). In addition, volunteers with polymorphisms of the CES1 gene indicative of being a poor metaboliser of methylphenidate were excluded. One participant was excluded based on this criterion.

All subjects gave written informed consent. The study was carried out in accordance with the declaration of Helsinki and approved by the medical ethical committee of Maastricht University.

\section{Design}

The study was conducted according to a double-blind, placebo-controlled, four-way crossover design. Between the testing days, a period of at least $48 \mathrm{~h}$ elapsed, but generally testing days were scheduled approximately 1 week apart. Each participant received one of four single treatments including placebo (PLA) and 10, 20 and $40 \mathrm{mg}$ methylphenidate (M10, M20 and M40) on each testing day. The order of the treatments was randomized following a Williams Latin square design resulting in four different sequences constructed using SAS programme. 
Dependent measures

\section{EEG measurement}

During two response preparation tasks, EEG was measured using 11 electrodes placed on the scalp, according to the 10-20 system at the Fz, F3, F4, Cz, C3, C4, Pz, P3, P4, O1 and $\mathrm{O} 2$ electrode positions. The remaining electrodes consisted of four to register vertical and horizontal eye movements, two on the mastoids for reference and one on the forehead as ground. Data were recorded with a $1,000-\mathrm{Hz}$ sample rate and filtered online between 0.05 and $100 \mathrm{~Hz}$. Offline, data were first screened for artefacts and a low pass filter of $10 \mathrm{~Hz}$ was applied on all data. Next, epochs were extracted from the continuous EEG. Each epoch lasted $5,100 \mathrm{~ms}$, starting $100 \mathrm{~ms}$ before S1 and ending $1,000 \mathrm{~ms}$ after S2. A baseline correction was applied to the whole epoch, using the $100 \mathrm{~ms}$ interval preceding S1 as reference. Averaging the sequential epochs yielded a S1 stimulus locked event-related potential (ERP). CNV amplitude was calculated by averaging the amplitude over the last $100 \mathrm{~ms}$ before S2. Since the CNV amplitude was expected to be maximal at the central electrodes (Brunia 1988; Klorman and Bentsen 1975; van Boxtel and Brunia 1994), Cz, C3 and C4 were of main interest and are reported in the Results section.

\section{Response preparation tasks}

CNV stoplight task In the CNV stoplight task, participants watched the computer screen and were presented with a filled red circle (S1) on a black background. After $4 \mathrm{~s}$, the red circle turned green (S2). Subjects were instructed to respond to the green circle by pressing a button on a table mounted response box as fast as they could. Each test consisted of 32 trials. Reaction time to the onset of S2 was measured in each trial and averaged over the test.

CNV lines task A CNV task with a long preparation time can be boring, and participants may become less motivated to produce speeded responses to the imperative stimulus. This may have a detrimental effect on CNV amplitude. Therefore, a new task involving dynamic stimuli was designed. In the $\mathrm{CNV}$ lines task, S1 was the appearance of two red line drawings at the bottom left- and right-hand corner. The lines were oriented at a $90^{\circ}$ angle to each other and after appearing both moved towards the centre of the screen. After $4 \mathrm{~s}$, the lines crossed and turned green (S2). At this moment, participants pressed a response button as fast as possible. In two thirds of the trials, a horizontal yellow bar partially blocked the view of the lines as they moved towards the centre of the screen, but the lines were always visible at the moment of crossing. The yellow bar could be small or large, blocking less or more of the trajectory of the lines as they moved towards the centre. The trials with the small bar are collectively called 'lines 1', those with the large bar 'lines 2' and those without a bar 'lines 3'. Of each type, 25 trials were presented. Reaction time was measured and averaged per trial type. These three variations of the new paradigm and the standard paradigm were compared in order to find out which task led to optimal CNV amplitude.

\section{Subjective measures}

Participants completed two rating scales of subjective effects, the Profile of Mood States (POMS; McNair et al. 1992) and the Bond and Lader (B\&L) visual analogue scales (Bond and Lader 1974). These rating scales involved the presentation of $16(\mathrm{~B} \& \mathrm{~L})$ or 32 (POMS) bipolar items presented at the ends of a horizontal line on a computer touch screen. Each item consisted of two words describing mood states. Participants had to score their preference for either of the items in accordance with their mood by marking the line closer to one of the two words. Dependent measures were factor scores on the dimensions Alertness, Contentedness and Calmness (B\&L) and Depression, Anger, Fatigue, Vigour and Tension (POMS).

\section{Blood plasma values and physiological measures}

Blood samples were drawn in order to measure blood levels of the drug and neuroendocrine responses. Dependent variables were changes in levels of methylphenidate, prolactin and cortisol in blood during the testing days. Physiological measures including systolic and diastolic blood pressure and heart rate were also taken.

\section{Procedure}

A training session in which all behavioural tasks were practiced took place within 2 weeks before the first testing day. Participants abstained from alcohol during the last $24 \mathrm{~h}$ prior to each testing day and from caffeine containing drinks during the testing days. On testing days, they were collected at their home and arrived at the lab in fasted condition at either $8.00 \mathrm{am}$ or 8:30 am. Inclusion exclusion criteria were checked, including a drug screen (which tested presence of the following substances in urine: cannabis, opiates, cocaine, methamphetamine, benzodiazepines, amphetamines) and blood alcohol concentration measurement. Next, EEG electrodes and a catheter were placed, and participants were given a standardized meal for breakfast at 80 min per dose $(t=-80)$. At $t=0$, participants ingested four 
identically appearing capsules with water that all contained either PLA, M10, M20 or M40. Participants went through seven cycles of testing at $t=-60,30,60,120,180,240$ and 300 min relative to dosing. At $t=220$, a standard light lunch was served. Each cycle included a fixed order of the CNV stoplight task, the CNV lines task, POMS, B\&L, registration of heart rate and blood pressure and the drawing of blood samples. After collection of the blood samples, the catheter was cleaned with heparin dissolved in isotonic saline, and blood samples were centrifuged for $10 \mathrm{~min}$ at 4,000 rpm. Plasma was stored at $-20^{\circ} \mathrm{C}$ and frozen PK samples were moved to a $-80^{\circ} \mathrm{C}$ freezer. After the last measurement, the EEG electrodes and catheter were removed and participants were transported home by taxi.

\section{Data analysis}

Data were analysed using repeated measures analysis of covariance analysis. In this mixed model, the repeated measures of drug (independent variable) on the dependent variables (mean $\mathrm{CNV}$ amplitude, reaction time, scores on POMS and Bond \& Lader, heart rate, blood pressure, cortisol and prolactin levels in blood, $T_{\max }$ and $C_{\max }$ ) were tested using baseline (measurement of the dependent variable at $t-60$ ) as a covariate and period (first, second, third or fourth testing day) as between subjects variable. Since treatment consisted of different doses of the same drug and the lower doses may have no or little effect on amplitude, response time and subjective measures, the likelihood of finding a main effect on these measures may be rather small, even though higher doses may have a significant effect. Therefore, main effects of drug were not evaluated for the amplitude and reaction time data and the subjective measures. Instead, a priori planned comparisons between each dose relative to placebo were tested for significance, at $p<0.05$, using LSD correction. This is not the case for blood plasma values and physiological measures, where even small doses of the drug were expected to exert significant effects on heart rate, blood pressure, cortisol and prolactin levels and $T_{\max }$ and $C_{\max }$. Therefore, main effects are reported for these measures at a significance level of $p<0.05$. Post hoc testing using LSD correction was done to find out which doses had an effect.

\section{Results}

CNV amplitude

Averaged CNV waves recorded during performance of response preparation tasks are shown in Fig. 1. Mean differences on $\mathrm{CNV}$ amplitude relative to morning baseline

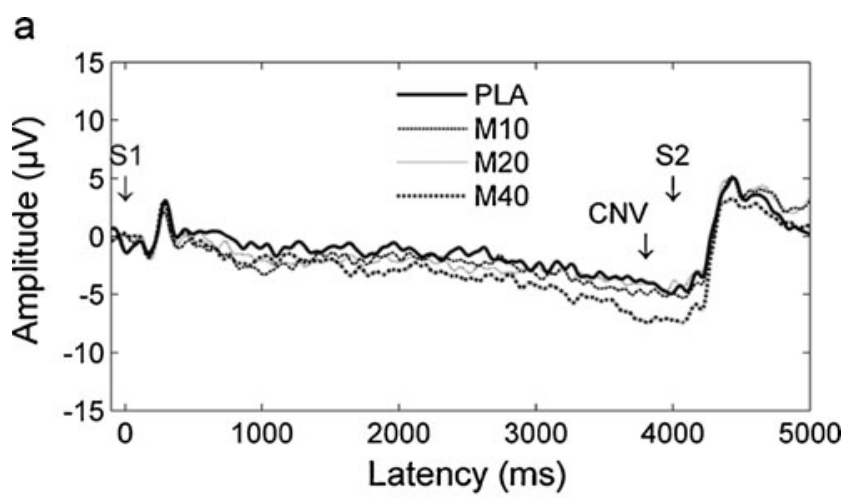

b

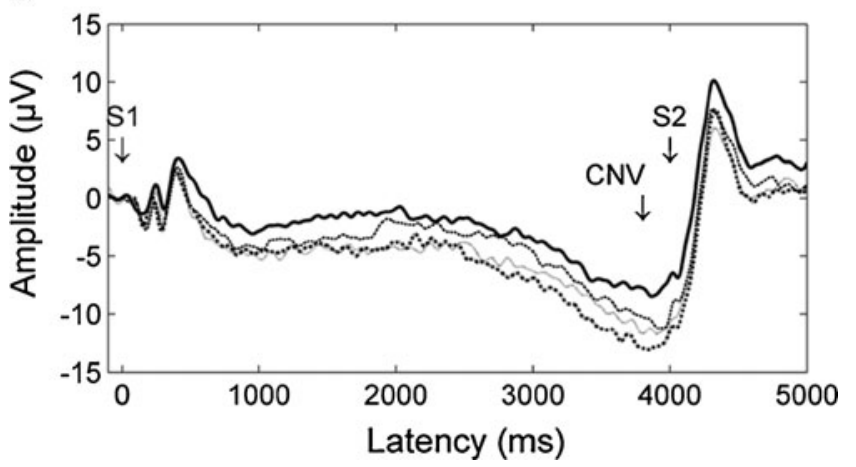

Fig. 1 Grand average ERPs showing a clear CNV wave during the stoplight (a) and lines 2 (b) response preparation tasks. The ERPs depicted were recorded at $\mathrm{Cz}$, at $t 240$ relative to dosing

are depicted in Fig. 2 for stoplight and lines 2 at Cz. Mean differences on $\mathrm{CNV}$ amplitude relative to morning baseline and results of significant difference testing are presented in Table 1.

Increases in CNV amplitude after methylphenidate measured at $t 60$ and $t 240$ account for, respectively, $27 \%$ and $46 \%$ of the total amount of significant differences observed in all paradigms and at all electrodes. More specifically, the effects at 1 and $4 \mathrm{~h}$ post-dosing were as follows (for a complete overview, see Table 1): Significant increases in CNV amplitude after methylphenidate during performance of the stoplight task were observed at $t 60$ after intake of $40 \mathrm{mg}$ of the drug at $\mathrm{Cz}$, $\mathrm{C} 3$ and $\mathrm{C} 4$ (Cz: $p<0.013, \mathrm{C} 3: p<0.035, \mathrm{C} 4: p<0.049$ ). At $t 60$, the amplitude was also larger after M10 at $\mathrm{Cz}(p<0.045)$. At $t 240$, M40 lead to a significantly increased amplitude at all three electrodes (Cz: $p<0.032, \mathrm{C} 3: p<0.028, \mathrm{C} 4: p<0.017$ ).

During performance of the lines task version 1 , amplitude was significantly larger after $40 \mathrm{mg}$ of methylphenidate compared to placebo at $t 240$ at the $\mathrm{Cz}$ electrode $(p<0.025)$. Analysis of the lines task version 2 showed significantly higher amplitudes after M40 at $t 60$ at the $\mathrm{C} 3$ electrode position $(p<0.035)$ and at $t 240$ at $\mathrm{C} 4(p<0.014)$. At $\mathrm{Cz}$, all doses led to higher $\mathrm{CNV}$ amplitude at 240 (M10: $p<0.025$, M20: $p<0.014$, M40: $p<0.006$ ). 
Fig. 2 Mean difference CNV amplitudes and reaction times relative to morning baseline at t30, 60, 120, 180, 240 and 300 min relative to dosing in the stoplight (amplitudes at $\mathrm{Cz}, \mathbf{a}$; reaction times, $\mathbf{c}$ ) and lines 2 (amplitudes at $\mathrm{Cz}, \mathbf{b}$; reaction times, d) response preparation tasks. Error bars are only shown for PLA (placebo) and M40 (methylphenidate, $40 \mathrm{mg}$ )
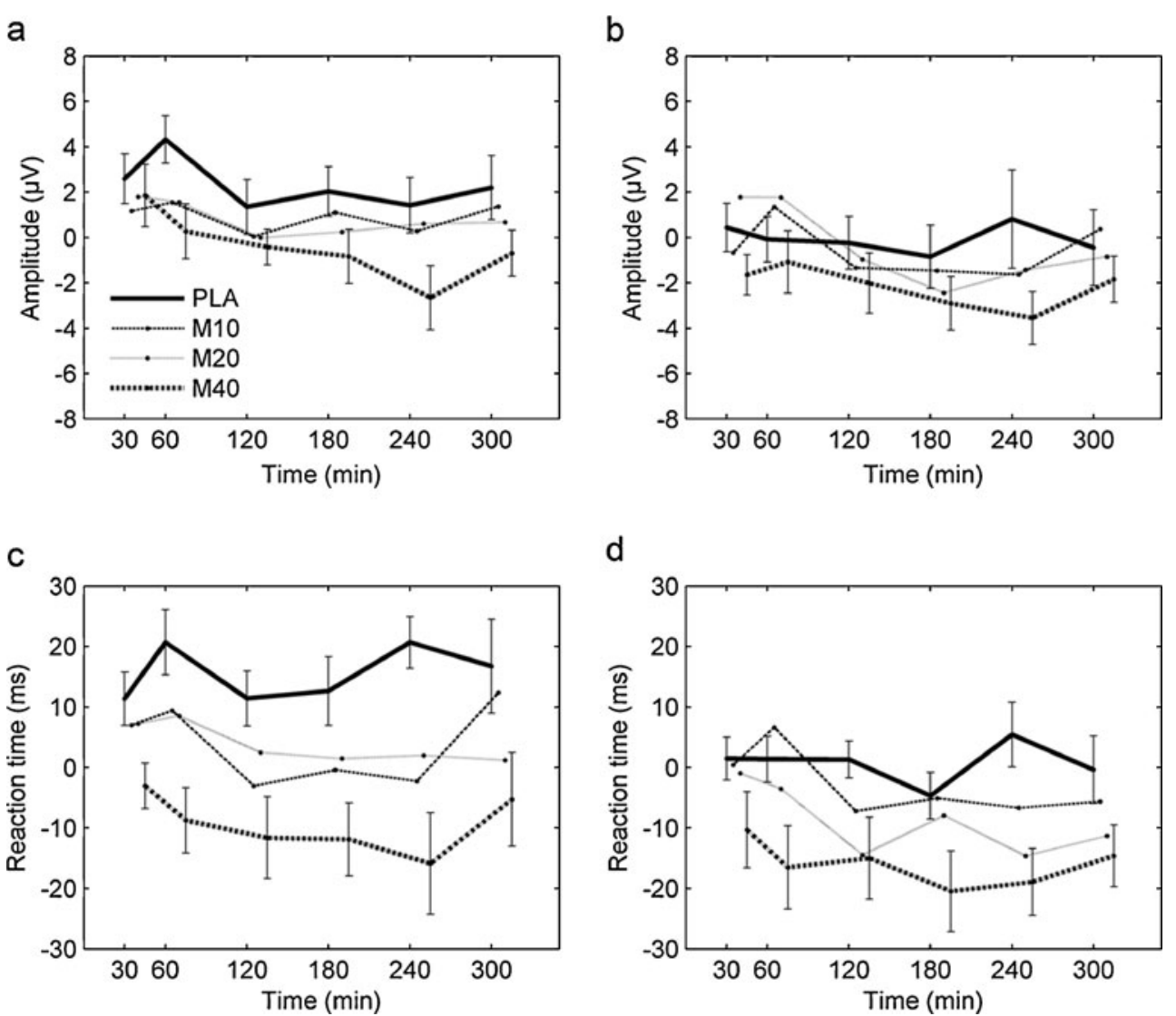

d

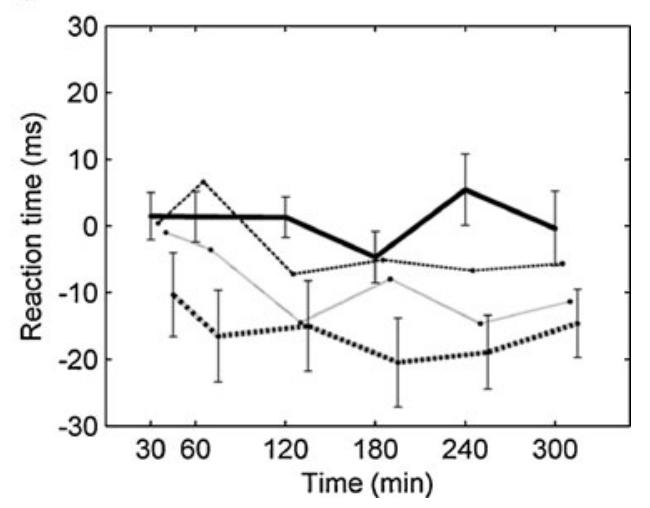

\section{Reaction time data}

Mean differences on reaction times relative to morning baseline are depicted in Fig. 2 for stoplight and lines 2. Mean differences on reaction time relative to morning baseline and results of significant difference testing are presented in Table 2.

Reaction times to the imperative stimulus in the stoplight task were shorter after $40 \mathrm{mg}$ of methylphenidate compared to placebo at all time points. At $t 240$, reaction times were also shorter after 10 and $20 \mathrm{mg}$ of methylphenidate.

On the lines task, version 1, reaction times were also shorter after $40 \mathrm{mg}$ of methylphenidate at $t 60, t 120, t 240$ and $t 300$. On version 2 of the lines task, reaction times were shorter after $40 \mathrm{mg}$ from $t 60$ to $t 300$ and after all doses at $t 120$. Reaction times were also shorter after the two lower doses at $t 120$ and $t 240$. Finally, M40 decreased reaction times on the lines 3 task on all time points. In addition, reaction times were shorter after $10 \mathrm{mg}$ of methylphenidate at $t 120$ and $t 240$.

\section{Subjective measures}

The Bond \& Lader factor scores indicated that participants felt more alert between 1 and $2 \mathrm{~h}$ after 20 and $40 \mathrm{mg}$ drug intake and more content from 1 to $3 \mathrm{~h}$ after $20 \mathrm{mg}$ of methylphenidate. Furthermore, analysis showed increased scores for calmness after $40 \mathrm{mg}$ of methylphenidate at $t 120$ but decreased scores after $10 \mathrm{mg}$ at $t 180$ and $t 300$.

Analysis of POMS factor scores indicated that after methylphenidate, participants experienced improved mood (all doses) and less anger (20 mg) compared to placebo between 1 and $3 \mathrm{~h}$ after drug intake. Factor scores indicated less fatigue at $t 60, t 120$ and $t 240$ after 20 and $40 \mathrm{mg}$ of methylphenidate, more vigour from 1 to $4 \mathrm{~h}$ after methylphenidate intake (all doses) and less tension after $40 \mathrm{mg}$ of methylphenidate at $t 30$ and $t 300$.

\section{Blood plasma values}

Mean levels of cortisol and prolactin in blood and results of significant difference testing are presented in Table 3. Methylphenidate significantly increased cortisol levels. At $t 60$, cortisol levels were significantly higher after all doses of methylphenidate when compared to placebo $\left(F_{3,41.43}=9.207\right.$, $p<0.001)$. At $t 120\left(F_{3,40.71}=11.964, p<0.001\right), t 180\left(F_{3}\right.$, $41.86=8.238, p<0.001)$ and $t 300\left(F_{3,39.02}=8.663, p<0.001\right)$ cortisol levels were significantly higher after M20 and M40 but not M10. At $t 240$, there was no effect of drug on cortisol levels $\left(F_{3,39.24}=0.647, p>0.05\right)$. 


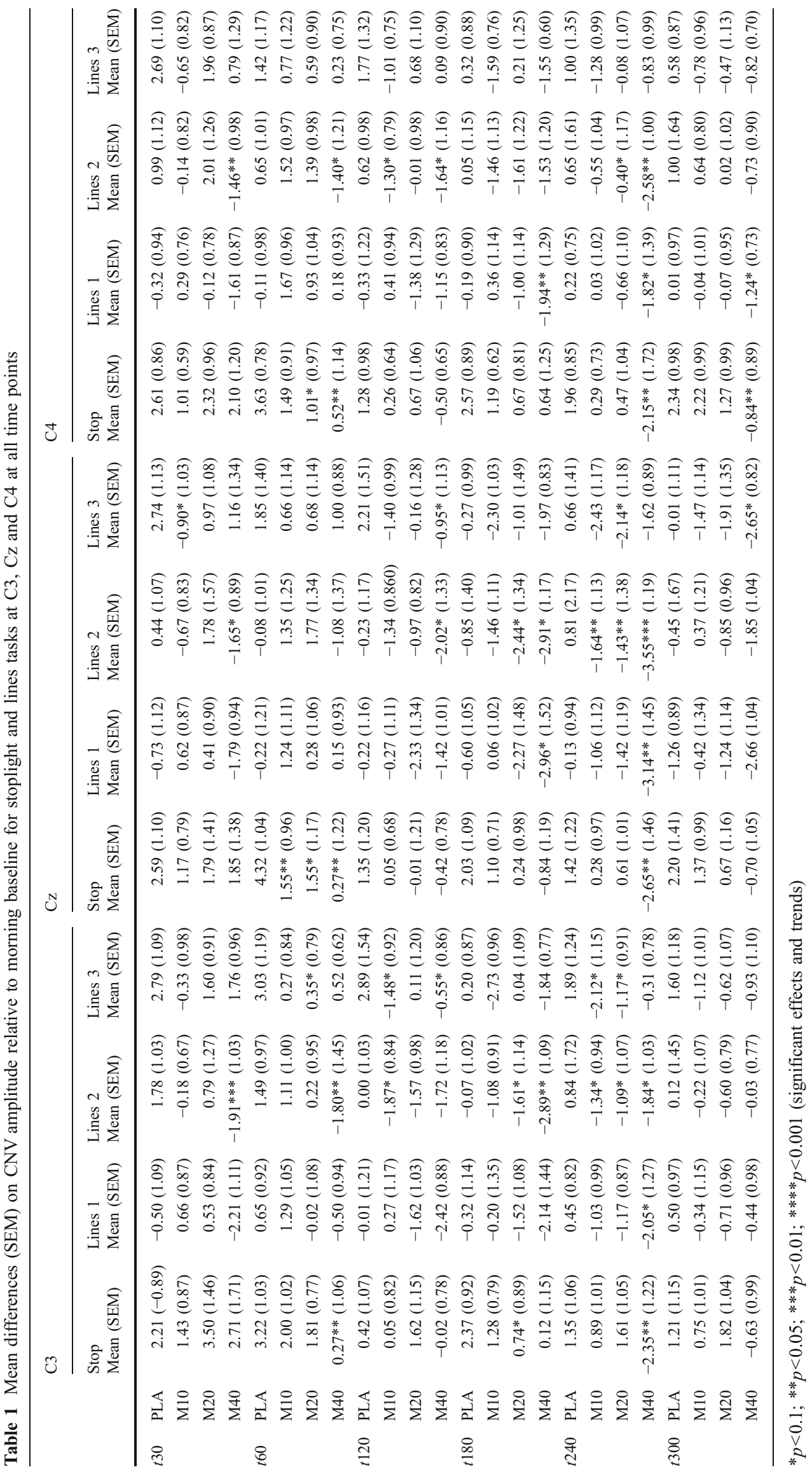


Table 2 Mean differences (SEM) on reaction times relative to morning baseline for stoplight and lines tasks
$* p<0.1 ; * * p<0.05 ; * * * p<0.01$; $* * * * p<0.001$ (significant effects and trends)

\begin{tabular}{|c|c|c|c|c|c|}
\hline & & Stoplight & Lines 1 & Lines 2 & Lines 3 \\
\hline & & Mean (SEM) & Mean (SEM) & Mean (SEM) & Mean (SEM) \\
\hline \multirow[t]{4}{*}{$t 30$} & PLA & $11.4(4.4)$ & $5.4(4.4)$ & $1.5(3.5)$ & $-0.1(4.3)$ \\
\hline & M10 & $7.0(6.3)$ & $4.0(3.3)$ & $0.4(4.6)$ & $-5.5(2.6)$ \\
\hline & M20 & $7.3(4.9)$ & $6.2(4.0)$ & $-1.0(3.1)$ & $1.2(4.1)$ \\
\hline & M40 & $-3.1 * *(3.8)$ & $-3.6(5.6)$ & $-10.3(6.3)$ & $-12.6^{* *}(5.4)$ \\
\hline \multirow[t]{4}{*}{$t 60$} & PLA & $20.7(5.4)$ & $5.9(4.6)$ & $1.4(3.8)$ & $2.4(4.2)$ \\
\hline & M10 & $9.4(7.1)$ & $5.7(3.7)$ & $6.6(6.0)$ & $0.7(5.4)$ \\
\hline & M20 & $8.5(6.0)$ & $1.7(3.7)$ & $-3.5(4.8)$ & $-6.3(4.4)$ \\
\hline & M40 & $-8.7 * * *(5.4)$ & $-9.4 * *(5.9)$ & $-16.5 * *(6.9)$ & $-14.8 * *(6.5)$ \\
\hline \multirow[t]{4}{*}{$t 120$} & PLA & $11.4(4.5)$ & $6.0(4.6)$ & $1.3(3.0)$ & $-3.7(4.5)$ \\
\hline & M10 & $-3.1(6.4)$ & $-2.0(2.7)$ & $-7.2 * *(3.5)$ & $-11.7 * * *(2.7)$ \\
\hline & M20 & $2.5(4.4)$ & $-4.4(3.1)$ & $-14.5 * *(3.4)$ & $-11.9(3.9)$ \\
\hline & M40 & $-11.6^{* * *}(6.8)$ & $-9.5 * *(5.5)$ & $-15.0 * *(6.8)$ & $-20.2 * * *(6.0)$ \\
\hline \multirow[t]{4}{*}{$t 180$} & PLA & $12.6(5.7)$ & $0.6(4.6)$ & $-4.7(3.9)$ & $-6.3(5.2)$ \\
\hline & M10 & $-0.4(9.3)$ & $1.2(2.9)$ & $-5.1(4.2)$ & $-8.7(3.0)$ \\
\hline & M20 & $1.5(5.9)$ & $-1.5(2.7)$ & $-8.0(3.2)$ & $-10.2(5.2)$ \\
\hline & M40 & $-11.9 * *(6.1)$ & $-11.2 *(5.8)$ & $-20.5 * *(6.7)$ & $-22.0 * * *(6.2)$ \\
\hline \multirow[t]{4}{*}{$t 240$} & PLA & $20.7(4.3)$ & $3.5(3.8)$ & $5.4(5.4)$ & $-4.3(5.2)$ \\
\hline & M10 & $-2.3 * *(9.1)$ & $-3.0(2.7)$ & $-6.7 * * *(4.1)$ & $-11.6 * *(2.2)$ \\
\hline & M20 & $2.0 * *(3.9)$ & $-1.6(4.9)$ & $-14.6 * * *(3.8)$ & $-10.8(5.1)$ \\
\hline & M40 & $-15.9 * * * *(8.6)$ & $-10.2 * *(5.7)$ & $-18.9 * * * *(5.7)$ & $-19.1 * * *(5.8)$ \\
\hline \multirow[t]{4}{*}{$t 300$} & PLA & $16.7(7.8)$ & $4.4(4.5)$ & $-0.4(5.6)$ & $-5.8(5.4)$ \\
\hline & M10 & $12.4(8.1)$ & $2.2(3.4)$ & $-5.6(4.7)$ & $-8.5(2.6)$ \\
\hline & M20 & $1.2 *(5.0)$ & $-2.9(3.1)$ & $-11.3(3.5)$ & $-14.2(4.9)$ \\
\hline & M40 & $-5.3 * *(8.0)$ & $-7.0 * * *(4.7)$ & $-14.6^{* *}(5.2)$ & $-16.8 * *(5.8)$ \\
\hline
\end{tabular}

Prolactin levels were lower after all doses of methylphenidate in comparison to placebo from $t 60$ to $t 180(t 60$ : $F_{3,36.32}=13.247, p<0.001 ; t 120: F_{3,38.18}=32.293, p<0.001$, $\left.t 180: F_{3,39.97}=29.558, p<0.001\right)$ and after M20 and M40 at $t 240\left(F_{3,37.11}=4.702, p<0.01\right)$ At $t 300$, the effect was no longer significant $\left(F_{3,37.52}=0.945, p>0.05\right)$.

Maximum methylphenidate concentration in blood differed significantly between treatment conditions $\left(C_{\max }\right.$ : M10 mean $(\mathrm{SEM})=4.9(0.4)$; M20 mean $(\mathrm{SEM})=9.3(0.7)$; M40 mean $\left.(\mathrm{SEM})=17.2(1.2), F_{2,30}=140.130, p<0.001\right) . T_{\max }$ was equal for all treatments (mean $(\mathrm{SEM})=2.9(0.2), F_{2,30}=0.134$, $p>0.05)$.

\section{Physiological measures}

Absolute baseline values of physiological measures and mean differences relative to morning baseline and results of significant difference testing are presented in Table 3. Methylphenidate (20 and $40 \mathrm{mg}$ ) significantly increased heart rate compared to placebo from 1 up to $5 \mathrm{~h}$ after drug administration ( $t 60: F_{3}$, $43.88=10.194, p<0.001 ; t 120: F_{3,44.04}=14.395, p<0.001 ; t 180$ : $F_{3,42.78}=13.325, p<0.001 ; t 240: F_{3,38.97}=9.195, p<0.001$; t300: $\left.F_{3,41.84}=7.271, p<0.001\right)$. At $t 120$ and $t 180$, all doses significantly increased heart rate. Systolic blood pressure was significantly higher after M20 and M40 compared to placebo at $t 60\left(F_{3,40.13}=5.433, p<0.01\right)$ and after all doses at $t 120$ $\left(F_{3,40.46}=5.178, p<0.01\right)$. At $t 180, t 240$ and $t 300$, there was no main effect of drug on systolic blood pressure, but systolic blood pressure was higher compared to placebo after M10 ( $t 180: p<0.05$; $t 240: p<0.05$; $t 300: p<0.05)$ and M20 ( $t 180$ : $p<0.05$; $t 240: p<0.05)$ as was revealed by the planned contrasts. Diastolic blood pressure significantly increased $1 \mathrm{~h}$ after intake of 20 and $40 \mathrm{mg}$ of methylphenidate compared to placebo ( $t 60$ : $\left.F_{3,42.39}=5.279, p<0.01\right)$. This effect remained significant until $4 \mathrm{~h}$ after drug intake $\left(t 120: F_{3,43.39}=4.808\right.$, $p<0.01 ; t 180: F_{3,43.73}=4.468, p<0.01 ; t 240: F_{3,42.04}=3.796$, $p<0.05)$.

\section{Discussion}

In the current study, the effects of different doses of methylphenidate on the late $\mathrm{CNV}$ wave were assessed in order to explore the utility of the CNV amplitude as a marker of dopamine activity. In line with the expectations, methylphenidate dose dependently increased CNV ampli- 
Table 3 Means (SEM) of cortisol and prolactin levels in blood, absolute baseline values and mean differences (SEM) relative to morning baseline for heart rate, systolic and diastolic BP at all time points

\begin{tabular}{|c|c|c|c|c|c|c|}
\hline & & Cortisol & Prolactin & Heart Rate & BP systolic & BP diastolic \\
\hline & & Mean (SEM) & Mean (SEM) & Mean (SEM) & Mean (SEM) & Mean (SEM) \\
\hline \multirow[t]{4}{*}{$\mathrm{BL}$} & PLA & 491 (27) & $11.4(0.9)$ & $66.3(2.2)$ & $133.9(3.3)$ & $73.8(3.8)$ \\
\hline & M10 & $504(28)$ & $11.6(1.2)$ & $66.7(2.7)$ & $130.6(2.5)$ & $71.8(2.8)$ \\
\hline & M20 & $576(27)$ & $13.6(1.3)$ & $67.7(2.3)$ & $133.1(3.0)$ & $70.7(1.7)$ \\
\hline & M40 & $512(43)$ & $11.8(1.2)$ & $66.3(2.5)$ & $133.2(2.7)$ & $72.7(1.7)$ \\
\hline \multirow[t]{4}{*}{$t 30$} & PLA & & & $-2.1(1.4)$ & $-0.2(1.8)$ & $-0.5(1.6)$ \\
\hline & M10 & & & $-3.1(1.4)$ & $-1.0(2.1)$ & $-0.8(3.0)$ \\
\hline & M20 & & & $-2.5(1.1)$ & $-1.8(2.0)$ & $0.8(1.3)$ \\
\hline & M40 & & & $-2.9(0.9)$ & $-1.8(2.0)$ & $1.1(1.7)$ \\
\hline \multirow[t]{4}{*}{$t 60$} & PLA & $325(21)$ & $9.0(0.6)$ & $-6.8(1.2)$ & $-6.8(2.7)$ & $-2.7(3.2)$ \\
\hline & M10 & $405 *(35)$ & $7.6^{* *}(1.0)$ & $-3.6(2.0)$ & $-1.5(1.6)$ & $2.2(3.9)$ \\
\hline & M20 & $454 * *(31)$ & $7.0 * * *(0.6)$ & $-0.5^{* *}(1.4)$ & $0.9^{* *}(2.3)$ & $6.4 * *(1.5)$ \\
\hline & M40 & $510 * * *(32)$ & $6.4 * * *(0.9)$ & $2.9^{* * *}(2.1)$ & $2.9^{* * *}(2.4)$ & $5.7 * *(2.3)$ \\
\hline \multirow[t]{4}{*}{$t 120$} & PLA & $300(18)$ & $8.5(0.7)$ & $-9.6(1.1)$ & $-5.5(1.8)$ & $-0.6(2.9)$ \\
\hline & M10 & $332(30)$ & $6.4 * * *(0.9)$ & $-5.8 *(1.4)$ & $2.3 *(2.4)$ & $2.2(3.3)$ \\
\hline & M20 & $409 * *(31)$ & $5.8^{* * *}(0.7)$ & $-2.4 * * *(1.4)$ & $0.8 *(2.6)$ & $6.6^{*}(1.7)$ \\
\hline & M40 & $481 * * *(35)$ & $4.4 * * *(0.4)$ & $0.9 * * *(2.2)$ & $3.7 * * *(2.3)$ & $5.6 * *(2.2)$ \\
\hline \multirow[t]{4}{*}{$t 180$} & PLA & $313(21)$ & $7.9(0.7)$ & $-9.8(1.1)$ & $-4.6(2.3)$ & $-1.7(3.8)$ \\
\hline & M10 & 347 (25) & $6.4 * * *(0.8)$ & $-5.5^{*}(1.6)$ & $2.0 *(1.5)$ & $0.4(3.3)$ \\
\hline & M20 & $411 * *(28)$ & $5.8 * * *(0.7)$ & $-2.6 * * *(1.6)$ & $0.7 *(2.1)$ & $6.1 * *(1.9)$ \\
\hline & M40 & $411 * * *(30)$ & $4.9 * * *(0.7)$ & $1.3^{* * *}(1.8)$ & $-0.2(2.5)$ & $3.3 *(1.6)$ \\
\hline \multirow[t]{4}{*}{$t 240$} & PLA & $400(31)$ & $10.1(1.1)$ & $0.2(1.6)$ & $-0.4(2.5)$ & $-5.0(3.0)$ \\
\hline & M10 & 419 (24) & $9.1(0.8)$ & $1.3(1.6)$ & $5.0 *(2.1)$ & $-0.1(3.9)$ \\
\hline & M20 & $423(28)$ & $8.0 * *(0.8)$ & $4.9 * *(2.0)$ & $5.3 *(2.0)$ & $2.9 *(1.5)$ \\
\hline & M40 & 457 (24) & $6.8^{* *}(0.8)$ & $7.9^{* * *}(1.8)$ & $2.9(1.9)$ & $2.5^{* *}(1.6)$ \\
\hline \multirow[t]{4}{*}{$t 300$} & PLA & $281(16)$ & $9.8(0.8)$ & $1.0(1.6)$ & $-3.0(2.4)$ & $-3.1(3.0)$ \\
\hline & M10 & $312(21)$ & $9.3(1.0)$ & $0.5(1.6)$ & $3.7 *(1.8)$ & $0.3(3.2)$ \\
\hline & M20 & $354 * *(18)$ & $9.6(1.0)$ & $4.4^{*}(1.3)$ & $1.2(2.3)$ & $2.2(1.3)$ \\
\hline & M40 & $369 * * *(19)$ & $8.0(0.7)$ & $6.6^{* *}(1.6)$ & $-1.9(2.2)$ & $0.4(1.9)$ \\
\hline
\end{tabular}

$B P$ blood pressure

${ }^{*} p<0.05 ; * * p<0.01 ; * * * p<0.001$ (significant effects)

tude and decreased reaction time in both response preparation paradigms. Furthermore, subjective measures indicated that participants experienced improved mood, felt more alert and vigorous and less angry and tired after methylphenidate. Physiological measures including blood pressure and heart rate increased, confirming previous findings (Volkow et al. 1996). These results indicate that dopamine activity increases response readiness as measured by the $\mathrm{CNV}$ paradigm.

CNV has been previously reported to be sensitive to dopaminergic modulation (Amabile et al. 1986; Kopell et al. 1974; Oishi et al. 1995; Tecce 1991; Tecce and Cole 1974; Tecce et al. 1975). However, little was known about dose-related effects. In the present study, the effects on reaction time and $\mathrm{CNV}$ amplitude could be detected after a dose of methylphenidate as low as $10 \mathrm{mg}$, demonstrating the sensitivity of the CNV paradigm to changes in dopamine availability. In support of a dose-response relationship, the effects were most prominently and consistently observed after the highest dose of methylphenidate. Importantly, the current effects are measured on the late $\mathrm{CNV}$ wave. Previous studies, using shorter intervals between S1 and S2 (Luthringer et al. 1999), may possibly have measured a composite of the early and late wave. An internal validation of the paradigms used in this study is provided by correlation analysis, which revealed consistent correlations between the difference scores for response time and $\mathrm{CNV}$ amplitude at $\mathrm{Cz}$ in the $40 \mathrm{mg}$ of methylphenidate condition in all paradigms at all time points, ranging between 0.46 and 0.96 with average of 0.78 . This correlation also emerged for the 
lower doses but a little less consistent, which is again indicative of a dose-response relationship. The lower doses may generate more variance which may less often lead to significant correlations.

Because methylphenidate inhibits re-uptake of dopamine, but also of noradrenaline (Arnsten and Dudley 2005), it cannot be stated with absolute certainty whether the current findings should be ascribed solely to increased dopamine levels. Dopamine levels in the brain cannot be measured directly, but changes in prolactin level in blood are a good surrogate marker since the prolactin level is known to rise as the dopamine level decreases and vice versa (Ben-Jonathan 1985). The decrease in prolactin levels observed here suggests that methylphenidate did successfully increase central dopamine levels.

Methylphenidate not only enhanced CNV amplitude but also increased response speed. As Fan et al. (2007) suggested, it seems that anticipation of the response, as reflected by $\mathrm{CNV}$ amplitude, improves response preparation and execution. Between S1 and S2, two waves can be observed, the early and the late CNV wave (Klorman and Bentsen 1975). In this study, the late CNV wave was investigated. The late wave is thought to be a mixture of a readiness potential and stimulus preceding negativity (Brunia and van Boxtel 2001). Improved performance may be the result of better motor preparation, increased anticipatory attention or a combination of both.

Based on the literature, it was expected that methylphenidate levels in the blood would peak $2 \mathrm{~h}$ after drug intake (Spencer et al. 2006; Volkow et al. 2002). In the current study, $T_{\max }$ was observed somewhat later, almost $3 \mathrm{~h}$ after intake. Although methylphenidate reaches a plateau between 2 and $3 \mathrm{~h}$, a delay in reaching $T_{\max }$ may possibly be related to the composition of the breakfast (Patrick et al. 2007). Behavioural effects already appeared at $30 \mathrm{~min}$ after drug intake and were still present after $5 \mathrm{~h}$. The effects on the EEG measures were more dispersed in time. Moreover, the effects clustered mainly around two time points, at approximately 1 and $4 \mathrm{~h}$ after drug intake. In other words, the effects are observed relatively shortly after drug intake and $1 \mathrm{~h}$ after $T_{\max }$.

The current method does not allow source localization. However, previous research suggests that the CNV is generated in the basal ganglia (Fan et al. 2007; Nagai et al. 2004). Taking into account the neuroanatomic projections of the dopaminergic pathways, the effect observed $1 \mathrm{~h}$ after drug intake may be mediated by a fast response of the nigrostriatal pathway, being responsible for an early attention enhancing effect. This idea is supported by our observation that participants felt more alert this time point. The late effect, on the other hand, is more likely to be mediated by the mesocortical pathway, which may be responsible for the top-down control of anticipatory processes affecting response readiness (Brunia and van Boxtel 2001; Fan et al. 2007). Alternatively, the schedule at testing days may have played a role in the timing of the effects. Whereas participants were probably rather energetic at $t 60$ and $t 240$, before which they just had a lunch break, they may have been less focused at $t 120$ and $t 180$. However, this only partly fits with the subjective effects reported by the participants.

The pattern of effects was quite similar for behavioural and EEG data. Both measures were modulated the most in the stoplight and lines 2 version of the task. There were only subtle differences between these tasks with respect to the methylphenidate effect on both response time and amplitude. However, since the lines 2 version is a little more attractive to participants, this task may be preferred for future use.

Generalization of the results may be limited by the fact that only male participants were included. Furthermore, taking into account the number of tasks administered, the testing days may have been rather demanding for the participants. This may have caused detrimental effects on performance or decrease of motivation. A limitation of the Bond and Lader visual analogue scale is that the calmness scale is based on very few (two) items. Therefore, interpretation of this scale warrants caution.

In conclusion, the current findings indicate that methylphenidate dose dependently increases response readiness. In sum, the CNV appears to be a good candidate biomarker for assessing changes in the dopaminergic function by treatments that either directly or indirectly target the dopamine system. Future research should aim to dissect the pharmacological selectivity of the CNV.

Acknowledgements This study was carried out at Maastricht University, Maastricht, the Netherlands and was sponsored by F. Hoffmann-La Roche Ltd., Basel, Switzerland. The authors SN, GV, WS, LS and WJR are employees of F. Hoffmann-La Roche. Employees of F. Hoffmann-La Roche were involved in designing the study, analysis and monitoring of the data and approval of the report. The authors have full control of all primary data and agree to allow review of the data if requested. The authors also would like to thank the following people for contributing to the study: Dr. Cees van Leeuwen, Irene Lelieveld, Conny Quaedflieg, Saskia Schneider, Natalie Valle and Lizzy Vuurman. The experiment complies with the current Dutch law.

Open Access This article is distributed under the terms of the Creative Commons Attribution Noncommercial License which permits any noncommercial use, distribution, and reproduction in any medium, provided the original author(s) and source are credited.

\section{References}

Amabile G, Fattapposta F, Pozzessere G et al (1986) Parkinson disease: electrophysiological (CNV) analysis related to pharmacological treatment. Electroencephalogr Clin Neurophysiol 64 (6):521-524

Arnsten AF, Dudley AG (2005) Methylphenidate improves prefrontal cortical cognitive function through alpha2 adrenoceptor and 
dopamine D1 receptor actions: relevance to therapeutic effects in attention deficit hyperactivity disorder. Behav Brain Funct 1(1):2

Ashton H, Rawlins MD (1978) Central nervous system depressant actions of clonidine and UK-14,304: partial dissociation of EEG and behavioural effects. Br J Clin Pharmacol 5(2):135-140

Ashton H, Millman JE, Telford R et al (1976) A comparison of some physiological and psychological effects of propranolol and diazepam in normal subjects. Br J Clin Pharmacol 3:551-559

Ashton H, Marsh VR, Millman JE et al (1980) Biphasic dose-related responses of the $\mathrm{CNV}$ (contingent negative variation) to I.V. nicotine in man. Br J Clin Pharmacol 10(6):579-589

Bares M, Rektor I (2001) Basal ganglia involvement in sensory and cognitive processing. A depth electrode CNV study in human subjects. Clin Neurophysiol 112(11):2022-2030

Bares M, Rektor I, Kanovsky P et al (2003) Cortical and subcortical distribution of middle and long latency auditory and visual evoked potentials in a cognitive (CNV) paradigm. Clin Neurophysiol 114 (12):2447-2460

Ben-Jonathan N (1985) Dopamine: a prolactin-inhibiting hormone. Endocr Rev 6(4):564-589

Bond A, Lader M (1974) The use of analogue scales in rating subjective feelings. Br J Med Psychol 47:211-218

Brunia CH (1988) Movement and stimulus preceding negativity. Biol Psychol 26(1-3):165-178

Brunia CH, van Boxtel GJ (2001) Wait and see. Int J Psychophysiol 43(1):59-75

Cooper NJ, Keage H, Hermens D et al (2005) The dose-dependent effect of methylphenidate on performance, cognition and psychophysiology. $\mathrm{J}$ Integr Neurosci 4(1):123-144

Fan J, Kolster R, Ghajar J et al (2007) Response anticipation and response conflict: an event-related potential and functional magnetic resonance imaging study. J Neurosci 27(9):2272-2282

Hansenne M, Pitchot W, Pinto E et al (2000) Serotonergic-1a activity and contingent negative variation. Biol Psychol 52(3):259-265

Hermens DF, Cooper NJ, Clark CR et al (2007) An integrative approach to determine the best behavioral and biological markers of methylphenidate. J Integr Neurosci 6(1):105-140

Iversen SD, Iversen LL (2007) Dopamine: 50 years in perspective. Trends Neurosci 30(5):188-193

Klorman R, Bentsen E (1975) Effects of warning-signal duration on the early and late components of the contingent negative variation. Biol Psychol 3(4):263-275

Kopell BS, Wittner WK, Lunde DT et al (1974) The effects of methamphetamine and secobarbital on the contingent negative variation amplitude. Psychopharmacologia 34(1):55-62

Leonard, B. E., McCartan, D., White, J., \& King, D. J. (2004). Methylphenidate: a review of its neuropharmacological, neuropsychological and adverse clinical effects. Hum Psychopharmacol 19(3):151-180

Luthringer R, Rinaudo G, Toussaint M et al (1999) Electroencephalographic characterization of brain dopaminergic stimulation by apomorphine in healthy volunteers. Neuropsychobiology 39 (1):49-56

McNair D, Lorr M, Droppleman L (1992) EdITS manual for the Profile of Mood States. Educational and Industrial Testing Service, San Diego

Mulder EJ, Linssen WH, de Geus EI (2002) Reduced sensory anticipation in migraine. Psychophysiology 39(2):166-174

Nagai Y, Critchley HD, Featherstone E et al (2004) Brain activity relating to the contingent negative variation: an fMRI investigation. Neuroimage 21(4):1232-1241
Nagai T, Takuma K, Kamei H et al (2007) Dopamine D1 receptors regulate protein synthesis-dependent long-term recognition memory via extracellular signal-regulated kinase $1 / 2$ in the prefrontal cortex. Learn Mem 14(3):117-125

Nieoullon A (2002) Dopamine and the regulation of cognition and attention. Prog Neurobiol 67(1):53-83

Oishi M, Mochizuki Y, Du C et al (1995) Contingent negative variation and movement-related cortical potentials in parkinsonism. Electroencephalogr Clin Neurophysiol 95(5):346-349

Papart P, Ansseau M, Timsit-Berthier M (1997) Influence of diazepam on contingent negative variation. Hum Psychopharmacol 12:95-98

Patrick KS, Straughn AB, Minhinnett RR et al (2007) Influence of ethanol and gender on methylphenidate pharmacokinetics and pharmacodynamics. Clin Pharmacol Ther 81(3):346-353

Rektor I, Kaiiovsky P, Bares M et al (2003) A SEEG study of ERP in motor and premotor cortices and in the basal ganglia. Clin Neurophysiol 114(3):463-471

Rektor I, Bares M, Kanovsky P et al (2004) Cognitive potentials in the basal ganglia - frontocortical circuits. An intracerebral recording study. Exp Brain Res 158(3):289-301

Rockstroh B, Elbert T, Lutzenberger W et al (1991) Effects of the anticonvulsant benzodiazepine clonazepam on event-related brain potentials in humans. Electroencephalogr Clin Neurophysiol 78 (2): $142-149$

Spencer TJ, Biederman J, Ciccone PE et al (2006) PET study examining pharmacokinetics, detection and likeability, and dopamine transporter receptor occupancy of short- and long-acting oral methylphenidate. Am J Psychiatry 163(3):387-395

Tecce JJ (1972) Contingent negative variation (CNV) and psychological processes in man. Psychol Bull 77(2):73-108

Tecce JJ (1991) Dopamine and CNV: studies of drugs, disease and nutrition. Electroencephalogr Clin Neurophysiol Suppl 42:153164

Tecce JJ, Cole JO (1974) Amphetamine effects in man: paradoxical drowsiness and lowered electrical brain activity (CNV). Science 185(149):451-453

Tecce JJ, Cole JO, Savignano-Bowman J (1975) Chlorpromazine effects on brain activity (contingent negative variation) and reaction time in normal women. Psychopharmacologia 43(3):293-295

van Boxtel GJ, Brunia CH (1994) Motor and non-motor aspects of slow brain potentials. Biol Psychol 38(1):37-51

Volkow ND, Wang GJ, Gatley SJ et al (1996) Temporal relationships between the pharmacokinetics of methylphenidate in the human brain and its behavioral and cardiovascular effects. Psychopharmacology (Berl) 123(1):26-33

Volkow ND, Wang GJ, Fowler JS et al (1998a) Dopamine transporter occupancies in the human brain induced by therapeutic doses of oral methylphenidate. Am J Psychiatry 155(10):1325-1331

Volkow ND, Wang GJ, Fowler JS et al (1998b) Differences in regional brain metabolic responses between single and repeated doses of methylphenidate. Psychiatry Res 83(1):29-36

Volkow ND, Fowler JS, Wang GJ et al (2002) Role of dopamine in the therapeutic and reinforcing effects of methylphenidate in humans: results from imaging studies. Eur Neuropsychopharmacol 12 (6):557-566

Volkow ND, Fowler JS, Wang GJ et al (2008) Methylphenidate decreased the amount of glucose needed by the brain to perform a cognitive task. PLoS ONE 3(4):e2017

Walter WG, Cooper R, Aldridge VJ et al (1964) Contingent negative variation: an electric sign of sensorimotor association and expectancy in the human brain. Nature 203:380-384 